Prepared in cooperation with the Commonwealth of Puerto Rico,

Department of Natural Resources

\title{
Marine geologic map of the southwestern insular shelf of Puerto Rico-Mayagüez to Cabo Rojo
}

By John S. Schlee, Rafael W. Rodriguez, Richard M.T. Webb, and M.A. Carlo

Geologic Investigations Series Map I-2615 